\title{
APPLICATION OF THE QUALITY BY DESIGN CONCEPT IN THE DEVELOPMENT OF QUERCETIN-LOADED POLYMERIC NANOPARTICLES
}

\author{
LUCIA RUXANDRA TEFAS ${ }^{1}$, LUCIA MARIA RUS ${ }^{2 *}$, MARCELA ACHIM ${ }^{1}$, LAURIAN VLASE ${ }^{1}$, \\ IOAN TOMUȚĂ ${ }^{1}$
}

I "Iuliu Hațieganu” University of Medicine and Pharmacy, Faculty of Pharmacy, Department of Pharmaceutical Technology and Biopharmaceutics, 41 Victor Babes Street, 400012, Cluj-Napoca, Romania

2 "Iuliu Hațieganu" University of Medicine and Pharmacy, Faculty of Pharmacy, Department of Drug Analysis, 6 Louis

Pasteur Street, 400349, Cluj-Napoca, Romania

*corresponding author: lucia.rus@umfcluj.ro

Manuscript received: February 2018

\begin{abstract}
The present study aimed at developing quercetin-loaded nanoparticles (QC-NP) by applying a quality by design (Qbd) approach. A risk analysis was performed to identify formulation and process parameters likely to impact the critical quality attributes (CQAs) of QC-NP. 6 variables, namely the polymer (PLGA), stabilizer (PVA) and QC concentrations, the stirring speed and the volumes of acetone and aqueous phase, were considered sources of variability in QC-NP quality. The variables were screened by experimental design to determine their effect on the CQAs of QC-NP. QC-NP were characterized for size, polydispersity, Zeta potential and entrapment efficiency, which were the CQAs. The QC-NP were nanosized, monodisperse and had negative surface charge. The percentage of entrapped QC ranged from $10.19 \%$ to $85.36 \%$. Of the studied variables, 4 exhibited main effects on the CQAs: the PLGA and PVA concentration, the volume of aqueous phase and the stirring speed. The overall results showed the usefulness of the QbD concept in the QC-NP development process.
\end{abstract}

\section{Rezumat}

Acest studiu a urmărit dezvoltarea de nanoparticule încărcate cu cvercetol (QC-NP) prin aplicarea conceptului de calitate prin design (QbD). O analiză de risc a fost realizată pentru a identifica parametri de formulare și proces capabili de a afecta atributele critice de calitate (ACC) a QC-NP. 6 variabile, respectiv concentraţia de polimer (PLGA), stabilizant (PVA) și QC, viteza de agitare şi volumul de acetonă şi fază apoasă au fost considerate surse de variabilitate a calității QC-NP. Variabilele au fost studiate printrun plan experimental pentru a determina efectul lor asupra ACC a QC-NP. QC-NP au fost caracterizate sub aspectul mărimii, polidispersiei, potențialului Zeta și eficienței încorporării, care au fost ACC. QC-NP au avut dimensiuni nanometrice, au fost monodisperse și au prezentat o sarcină de suprafață negativă. Procentul de QC încorporat a variat între 10,19\% și 85,36\%. Dintre variabilele studiate, 4 au prezentat efecte principale asupra ACC: concentraţia de PLGA și PVA, volumul de fază apoasă și viteza de agitare. În ansamblu, rezultatele arată utilitatea conceptului de QbD în procesul de dezvoltare a QC-NP.

Keywords: nanoparticles, quercetin, quality by design, design of experiments

\section{Introduction}

Nanotechnology is a rapidly expanding field and has been the focus of scientists in the last decades [56]. It is a multidisciplinary field with impressive recent advances in biomedicine, including drug delivery, gene therapy, diagnostics and imaging [7, 10, 46]. Drug delivery is a key research area in nanotechnology which is likely to revolutionize the healthcare field as it allows overcoming the limitations associated with conventional systems $[18,56]$. Conventional formulations often require frequent administration, imply rapid release of the drug, and thus could lead to toxicity [53]. On the other hand, nanoscaled drug delivery systems are taken up by cells more efficiently, have a reproducible modified release, improved efficiency, reduced side effects and better patient compliance $[46,53,55]$. Their performance is a result of their small size and large surface area which gives them unique physical and chemical properties and ability to ferry different types of molecules [10, 53]. Polymers play a significant role in drug delivery technology by providing controlled release of the active ingredient over longer periods of time and offering the possibility of incorporating and releasing both lipophilic and hydrophilic drugs [1]. Other advantages which make them a good candidate in developing drug delivery systems refer to optimized drug loading, increased drug solubility [52], improved stability for labile molecules [33] and drug targeting to specific diseased sites [40]. Aside from being effective, nanoparticles have to be safe and not induce toxicity. Compared to the non-degradable polymers, the biodegradable ones have certain advantages: themselves 
and their degradation products are non-toxic and avoid the accumulation of polymer in the body after multiple administrations by being cleared from the body by natural metabolic pathways [7, 29]. Therefore, biodegradable polymers are an important type of material used to engineer drug delivery systems [25]. Degradation occurs due to cleavage of the covalent bonds within their structure [52]. Among all polymers, a significant one with wide applications is poly-(lactic-co-glycolic) acid (PLGA), a biocompatible and biodegradable polymer, which is hydrolytically degraded to its monomers, lactic acid and glycolic acid [27]. Polymeric nanoparticles have been extensively studied in the past decades due to their increased stability and possibility of tailoring their characteristics through modifications of the polymer or the surface properties. They can be formulated for site-specific targeting and sustained release of the entrapped drug over a longer period of time (days or even weeks) [50].

Flavonoids which are naturally occurring phytochemicals exhibit important antioxidant, even anti-tumoural properties [21, 54]. Quercetin (3,3',4,5,7-pentahydroxyflavone, QC) a well-known flavonoid has received considerable attention due to its antioxidative, antiinflammatory and anticancerous effects [6]. However, QC has low water solubility and bioavailability [37]. Hence the necessity to conceive an efficient formulation such as a nanoparticulate delivery system for enhanced solubility and absorption of QC. Due to its impressive spectrum of pharmacological effects, developing QCloaded nanoparticulate systems has been the focus for scientists in recent years. Numerous types of vectors encapsulating QC have been described in the literature, including micelles [11], liposomes [57, $61]$, polymeric [19, 45] and solid lipid nanoparticles $[24,58]$.

In the pharmaceutical field, quality is regarded as a very important topic. Quality is a key feature that must be assured for all pharmaceutical products. Janet Woodcock, the Director for the Centre for Drug Evaluation and Research, in one of its papers (2004), defines quality through absence of contamination and the ability to ensure the therapeutic benefit mentioned on the label of the product [43]. Product quality refers to performance, robustness, trustworthiness, which have to be built into a product [47]. To assure the quality of a product, scientific tools such as Quality by Design (QbD) can be implemented. QbD is a concept first introduced a few decades ago by Dr. Joseph M. Juran and emphasizes the design of a product and manufacturing process to reach a certain predefined quality [26, 43]. In Dr. Juran's opinion, the quality of a product could be planned, and he believed that most quality inadequacies originate from the way in which the quality of the product was planned [60]. There are several regulatory documents which offer guidance in understanding how $\mathrm{QbD}$ assists in ensuring the quality of a product, and encourage the adoption of this concept by the pharmaceutical industry: International Conference on Harmonization (ICH) Q8 Pharmaceutical development, Q9 Quality risk management and Q10 Pharmaceutical quality system, Process Analytical Technology (PAT) and US FDA's Pharmaceutical cGMPs for $21^{\text {st }}$ century - a risk based approach [47].

According to the Annex on Pharmaceutical Development in the ICH Q8(R2) guideline, QbD is defined as "a systematic approach to development that begins with predefined objectives and emphasizes product and process understanding and process control, based on sound science and quality risk management" [17]. Such a scientific approach will provide the necessary knowledge and information from the development and manufacturing of a product, to minimize the risk and enhance the quality of the product [42]. QbD claims to understand the way in which the quality is influenced by formulation and process variables [26], therefore, the quality of the product can be assured by controlling the formulation and manufacturing process [41].

Design of Experiments (DoE), Process Analytical Technology (PAT) and risk assessment are tools that can be used in QbD [26]. DoE is a procedure for "determining the relationship between factors affecting a process and the output of that process" in a structured and organized way [17]. It is helpful for establishing the cause which produces variation in a response and determining a model which predicts a response. In DoE, the first step is to perform a screening of the variables to determine those with significant impact on the quality of the final product. Secondly, the optimization process is carried out to establish the best conditions for a desired outcome [32]. Because full factorial designs are often time consuming and require a numerous number of runs, especially if the number of investigated variables is high, sometimes fractional factorial experimental designs are preferred. As their name suggests, fractional factorial designs imply carrying out a fraction of the runs from the full factorial design [41].

The purpose of this work was to develop QC-loaded polymeric nanoparticles based on the biodegradable polymer PLGA by implementing QbD principles. Several formulation and process variables were evaluated with regard to their impact on the characteristics of the nanoparticles by means of DoE. Our goal was to identify from the list of investigated variables, the ones with significant effects on the quality of the final product.

\section{Materials and Methods}

Materials

QC and polyvinyl alcohol (PVA) (average MW 30000 70000) were obtained from Sigma-Aldrich (St. Louis, SUA). Resomer RG 502 H (PLGA) 50:50 (MW 13100) 
was purchased from Boehringer Ingelheim (Ingelheim am Rhein, Germany). Acetone was obtained from SC ChimReactiv SRL (Bucharest, Romania) and methanol and acetonitrile were purchased from LGC Standards GmbH (Wesel, Germany).

\section{Methods}

Differential scanning calorimetry (DSC) study

The DSC measurements were performed with a Mettler Toledo DSC822 calorimeter (Mettler Toledo, Columbus, USA). The thermal analyser was calibrated with an indium standard.

The thermal behaviour of QC, PLGA, PVA and also the binary physical mixtures 1:1 (w/w) of QC and each of the excipient were determined.

Approximately $2 \mathrm{mg}$ of sample were sealed in $40 \mu \mathrm{L}$ aluminium pans and further scanned at a heating rate of $10^{\circ} \mathrm{C} / \mathrm{min}$ over a temperature range of $25-400^{\circ} \mathrm{C}$, under nitrogen purge at $80 \mathrm{~mL} / \mathrm{min}$ flow. Empty and sealed standard aluminium pans were used as reference. Data were collected and analysed with STAR SW 12.10 software. The thermograms of the pure substances were compared to those of the binary mixtures.

QbD approach

According to the ICH Q8(R2), pharmaceutical development aims at designing a "quality product and manufacturing process to consistently deliver

the intended performance" [17]. Regulatory agencies recommend the implementation of the QbD concept in pharmaceutical development to obtain a product which best fits its purpose [36].

The key components of a QbD assisted pharmaceutical product development include the following: (1) the quality target product profile (QTPP) which identifies, (2) the critical quality attributes (CQAs) of the product, (3) the critical process parameters (CPPs), (4) assessment of the potential risk on the product's CQAs, (5) setting the design space, (6) establishment of a control strategy to ensure the required quality for the product, and (7) monitorization of the process performance and continuous improvement [17, 41, 60].

Determining the quality target product profile (QTPP) "The QTPP forms the basis of design for the development of the product" according to the ICH Q8(R2) guideline [17]. Considerations for establishing the QTPP may include dosage form, dosage strength, administration route, delivery system, pharmacokinetic characteristics and other quality product criteria such as stability, purity, sterility, drug release etc. [3, 17, 62]. Based on relevant literature information and the established knowledge space, the QTPP of QC-loaded nanoparticles has been defined and is presented in Table I along with targets and justification.

Table I

QTPP of QC-loaded PLGA nanoparticles

\begin{tabular}{|c|c|c|}
\hline Criterion & Target & Justification \\
\hline Dosage form & Nanoparticles & The size is a key factor in circulation half-life, cellular uptake and bio-distribution \\
\hline Administration route & Parenteral & $\begin{array}{l}\text { Delivery directly into the systemic circulation; bypasses the gastrointestinal tract; } \\
\text { the drug is immediately available to exhibit its therapeutic activity }\end{array}$ \\
\hline Therapeutic effect & Antioxidant & The product contains QC with antioxidant properties \\
\hline Drug release & Sustained release & Assures a constant drug concentration over a longer period of time \\
\hline
\end{tabular}

Determining the critical quality attributes (CQAs) and critical process parameters (CPPS) by risk analysis The risk assessment is a process which implies systematic organization of information in order to get insight of the potential sources of hazards, the impact the hazard could have and to take the necessary measures to reduce the risk [62]. Only a detailed understanding of the manufacturing process allows minimizing the risk through thorough control of the CPPs. Therefore, an overall risk assessment for the QC-loaded nanoparticles was performed in order to identify the formulation variables and process parameters affecting the CQAs of the product, as these parameters are likely to influence the QTPP of QC-loaded nanoparticles.

According to review of scientific literature, the size, size distribution, Zeta potential and entrapment efficiency are the most important characteristics of QC-loaded nanoparticles, and were therefore selected as relevant CQAs.

A qualitative risk assessment was carried out by Failure Mode and Effects Analysis (FMEA) method. In this regard, all potential factors that could affect the product quality were considered and organized systematically in an Ishikawa fishbone diagram. Using FMEA, the factors outlined in the Ishikawa diagram were prioritized based on the Risk Priority Number (RPN). The risk included probability of occurrence $(\mathrm{O})$, severity $(\mathrm{S})$ of the effects and detectability (D). For all factors, each of the three parameters was assigned a score, ranging from 1 to 5 , and the RPN was calculated with the following formula: RPN $=\mathrm{O} \times \mathrm{S} \times \mathrm{D}$. Based on the RPN, six high-risk parameters were identified as potentially impacting the QC-loaded nanoparticles' CQAs and were further evaluated by experimental design to reduce the risk to an acceptable range.

\section{Experimental design}

The influences of several formulation factors and process parameters on the QC-loaded nanoparticles' characteristics (or CQAs) were evaluated by experimental design. In this regard, Fractioned Factorial Design Resolution IV with six variables and two levels was generated with Modde 10 software (Umetrics, Umeå, Sweden). The fractional factorial screening 
FARMACIA, 2018, Vol. 66, 5

design helped identify the variables to be addressed or eliminated in further studies. The independent variables were the PLGA concentration $(\mathrm{mg} / \mathrm{mL})$, the PVA concentration $(\% \mathrm{w} / \mathrm{v})$, the QC concentration $(\mathrm{mg} / 10 \mathrm{~mL})$, the acetone volume $(\mathrm{mL})$, the aqueous phase volume $(\mathrm{mL})$ and the stirring speed (rpm). The symbols and variation levels for each independent variable are given in Table II.

The investigated dependent variables or the CQAs of the nanoparticles were as follows: the particle size $(n m)\left(Y_{1}\right)$, the size distribution expressed as the polydispersity index $\left(\mathrm{PdI}, \mathrm{Y}_{2}\right)$, the Zeta potential $(\mathrm{mV})\left(\mathrm{Y}_{3}\right)$ of the nanoparticles and the QC entrapment efficiency $(\%)\left(\mathrm{Y}_{4}\right) .19$ experimental runs were carried out according to the design matrix (Table III) in a random order to eliminate biased variance. The data were fitted by means of partial least squares with the statistical module of the Modde 10 software.

Three-dimensional response surface plots were generated to illustrate the effect between two variables on the response while keeping the others constant.

Table II

Independent variables and their levels of variation

\begin{tabular}{lcccc}
\hline \multirow{2}{*}{ Independent variable } & Symbol & \multicolumn{3}{c}{ Level of variation } \\
\cline { 3 - 5 } & & $\mathbf{- 1}$ & $\mathbf{0}$ & $+\mathbf{1}$ \\
\cline { 3 - 5 } & $\mathrm{X}_{1}$ & 5 & 10 & 15 \\
PLGA concentration $(\mathrm{mg} / \mathrm{mL})$ & $\mathrm{X}_{2}$ & 0.25 & 0.5 & 1 \\
PVA concentration $(\% \mathrm{w} / \mathrm{v})$ & $\mathrm{X}_{3}$ & 3 & 4 & 5 \\
QC concentration $(\mathrm{mg} / 10 \mathrm{~mL})$ & $\mathrm{X}_{4}$ & 3 & 5 & 7 \\
Acetone volume $(\mathrm{mL})$ & $\mathrm{X}_{5}$ & 255 & 340 & 425 \\
Stirring speed $(\mathrm{rpm})$ & $\mathrm{X}_{6}$ & 20 & 35 & 50 \\
Aqueous phase volume $(\mathrm{mL})$ & & &
\end{tabular}

Table III

Experimental design matrix

\begin{tabular}{ccccccccc}
\hline No. & Exp. name & Run order & $\mathbf{X}_{\mathbf{1}}$ & $\mathbf{X}_{\mathbf{2}}$ & $\mathbf{X}_{\mathbf{3}}$ & $\mathbf{X}_{\mathbf{4}}$ & $\mathbf{X}_{\mathbf{5}}$ & $\mathbf{X}_{\mathbf{6}}$ \\
\hline 1 & N1 & 7 & 5 & 0.25 & 3 & 3 & 255 & 20 \\
2 & N2 & 19 & 15 & 0.25 & 3 & 3 & 425 & 20 \\
3 & N3 & 2 & 5 & 1 & 3 & 3 & 425 & 50 \\
4 & N4 & 15 & 15 & 1 & 3 & 3 & 255 & 50 \\
5 & N5 & 3 & 5 & 0.25 & 5 & 3 & 425 & 50 \\
6 & N6 & 5 & 15 & 0.25 & 5 & 3 & 255 & 50 \\
7 & N7 & 6 & 5 & 1 & 5 & 3 & 255 & 20 \\
8 & N8 & 8 & 15 & 1 & 5 & 3 & 425 & 20 \\
9 & N9 & 12 & 5 & 0.25 & 3 & 7 & 255 & 50 \\
10 & N10 & 10 & 15 & 0.25 & 3 & 7 & 425 & 50 \\
11 & N11 & 4 & 5 & 1 & 3 & 7 & 425 & 20 \\
12 & N12 & 16 & 15 & 1 & 3 & 7 & 255 & 20 \\
13 & N13 & 18 & 5 & 0.25 & 5 & 7 & 425 & 20 \\
14 & N14 & 14 & 15 & 0.25 & 5 & 7 & 255 & 20 \\
15 & N15 & 13 & 5 & 1 & 5 & 7 & 255 & 50 \\
16 & N16 & 17 & 15 & 1 & 5 & 7 & 425 & 50 \\
17 & N17 & 1 & 10 & 0.5 & 4 & 5 & 340 & 35 \\
18 & N18 & 11 & 10 & 0.5 & 4 & 5 & 340 & 35 \\
19 & N19 & 9 & 10 & 0.5 & 4 & 5 & 340 & 35
\end{tabular}

Exp. - Experiment; $\mathrm{X}_{1}-\mathrm{PLGA}$ concentration $(\mathrm{mg} / \mathrm{mL}) ; \mathrm{X}_{2}-\mathrm{PVA}$ concentration $(\% \mathrm{w} / \mathrm{v}) ; \mathrm{X}_{3}-\mathrm{QC}$ concentration $(\mathrm{mg} / 10 \mathrm{~mL}) ; \mathrm{X}_{4}-$ Acetone volume (mL); $\mathrm{X}_{5}-$ Stirring speed (rpm); $\mathrm{X}_{6}-$ Aqueous phase volume $(\mathrm{mL})$

\section{Preparation of QC-loaded nanoparticles}

The nanoparticles were obtained by the nanoprecipitation method previously described [14], however with some modifications. Briefly, PLGA and QC were dissolved in acetone, and subsequently the organic solution was added in a drop wise manner to an aqueous PVA solution. The acetone was removed from the mixtures under continuous magnetic stirring with MultiStirrer 6 (VELP Scinetifica, Usmate Velate, Italy) over 4 hours, at room temperature. The resulting QCloaded nanoparticles were separated from the nonentrapped drug by centrifugation (Sigma, Osterode am Harz, Germany) at 25,000 rpm, for 30 minutes.

\section{Physicochemical characterization of QC-loaded nanoparticles \\ Particle size and particle size distribution analysis} The particle size and PdI of the QC-loaded nanoparticles were determined by dynamic light scattering using a Zetasizer Nano ZS (Malvern Instruments Ltd, Malvern, UK). $50 \mu \mathrm{L}$ of sample were diluted with purified water and further analysed at $25^{\circ} \mathrm{C}$, at a scattering angle of $90^{\circ}$. All measurements were performed in triplicate and are expressed as mean \pm standard deviation. 
Zeta potential analysis

The Zeta potential of the QC-loaded nanoparticles was assessed using the same Zetasizer by laser Doppler electrophoresis. Briefly, $300 \mu \mathrm{L}$ of sample was diluted with purified water and further analysed.

The measurement was carried out thrice for each sample and the results are given as mean \pm standard deviation.

\section{Entrapment efficiency analysis}

The amount of QC incorporated in the nanoparticles was assessed by an HPLC method. In this regard, the nanoparticles were mixed with methanol, and further diluted with a mixture of acetonitrile:water 75:25 $(\mathrm{v} / \mathrm{v})$ in a ratio of $1: 1$. After centrifugation, the supernatant was collected and analysed. The chromatographic system Agilent 1100 series (Agilent Technologies, Santa Clara, USA) consisted of a binary pump, an autosampler, a Gemini C18 column $(3 \mu \mathrm{m})$ and a UV-Vis detector. The mobile phase was acetonitrile: phosphoric acid $0.1 \% 30: 70(\mathrm{v} / \mathrm{v}) .5 \mu \mathrm{L}$ of sample were injected into the system and eluted at a flow rate of $0.6 \mathrm{~mL} / \mathrm{min}$, with the detection at $370 \mathrm{~nm}$. Data were collected and analysed with Agilent ChemStation Software. The entrapment efficiency (EE0 was calculated according to the following formula:

$$
\mathrm{EE}(\%)=\frac{\text { Entrapped drug concentration }}{\text { Total drug concentration }} \cdot 100
$$

\section{Results and Discussion}

\section{Differential scanning calorimetry}

The thermal behaviour for pure QC, PLGA and PVA, together with that of the physical mixtures of QCPLGA and QC-PVA are shown in Figure 1.

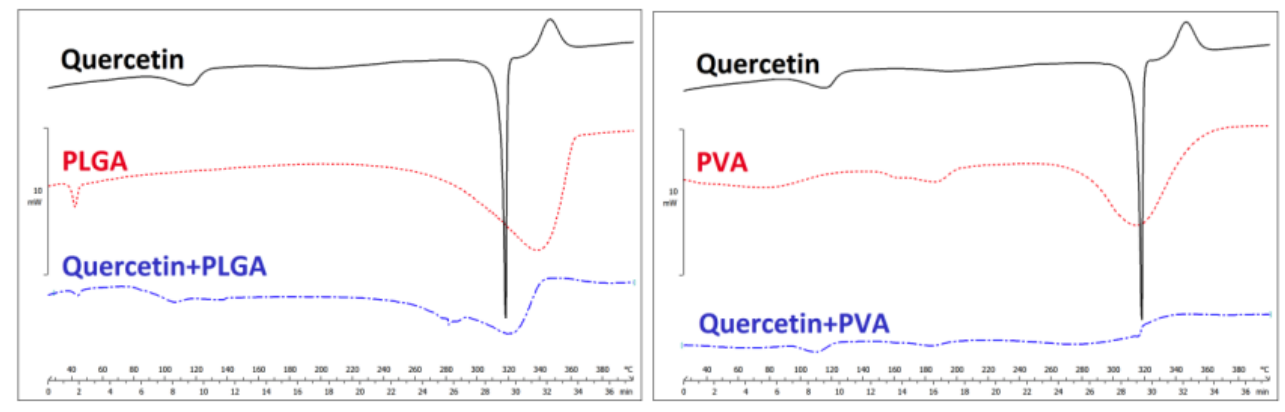

Figure 1.

DSC thermograms for pure QC, PLGA and PVA, and for QC-PLGA and QC-PVA physical mixtures

The thermogram for QC shows two characteristic endothermic peaks at $115.86^{\circ} \mathrm{C}$ and $317.19^{\circ} \mathrm{C}$ corresponding to its dehydration and melting, respectively, which is in agreement with data reported by Pool et al [39]. PLGA also exhibited two endothermic peaks for glass transition at $42.28^{\circ} \mathrm{C}$ and possibly degradation at $339.35^{\circ} \mathrm{C}$. Our findings are in accordance with previously published data [8].

Regarding the thermogram for PVA, our results are slightly different from those reported in the literature. According to El-kader et al, PVA shows three peaks at $83^{\circ} \mathrm{C}, 222^{\circ} \mathrm{C}$ and $292^{\circ} \mathrm{C}$ corresponding to glass transition, melting and degradation temperatures, respectively [13]. Our thermogram reveals a shift in the temperature peaks $\left(80.48^{\circ} \mathrm{C}, 187.16^{\circ} \mathrm{C}, 315.80^{\circ} \mathrm{C}\right)$ and the appearance of another endothermic peak $\left(160.84^{\circ} \mathrm{C}\right)$. The differences in results could be due to the fact that El-kader et al used PVA with a different molecular weight $(17,000)$.

The physical mixtures of QC-PLGA and QC-PVA exhibited a thermal behaviour similar to that observed for the pure substances. However, there were some shifts in temperature peaks and newly formed ones. These changes could be attributed to interactions between QC and the polymer [39], but it cannot be affirmed with certainty, since the endothermic melting peak for QC overlaps the degradation peak of the polymers.

QbD approach

Determining the quality target product profile (QTPP) The first step in the QbD approach is to define the QTPP based on current knowledge, then to identify the CQAs of the product and the process parameters which might influence the manufacturing process. According to the ICH Q8(R2) it is crucial to establish the QTPP as it "relates to quality, safety and efficacy" [17]. Therefore, as listed in Table I, we defined a nanoparticulate drug delivery system entrapping QC with sustained release, for parenteral use. The selected QTPP for our nanoparticulate system is in agreement with scientific literature and approved guidelines.

Determining the critical quality attributes (CQAs) and critical process parameters (CPPs) by risk analysis

The following step in the QbD approach was to identify the relevant CQAs of the QC-loaded nanoparticles to assure the desired QTPP. The CQA refers to a physical, chemical, biological or microbiological property of a product, and should be within a certain specified range [62]. CQAs are mainly associated with an active substance, excipients, intermediate products or the finished product. They are either 
FARMACIA, 2018, Vol. 66, 5

derived from the QTPP or are defined based on review of the literature [36]. According to relevant guidelines and prior knowledge, we have considered the size, polydispersity, Zeta potential and entrapment efficiency to be critical properties of nanoparticulate systems.

For nanoparticles, the size, polydispersity and surface properties play an important role in determining their in vivo distribution, toxicity, drug loading, drug release and even targeting ability [50]. These characteristics are in tight conjunction with the opsonisation and elimination by macrophage cells. It has been found that the passage of nanoparticles through the biological membranes is a size-dependent process. Thus, is has been established that generally, particles of less than $50 \mathrm{~nm}$ are transported by para-cellular passage, by slipping through the spaces between epithelial cells; particles not larger than $500 \mathrm{~nm}$ are taken up by endocytosis; particles up to $5 \mu \mathrm{m}$ undergo lymphatic uptake via the M cells of the Peyer's patches. These mechanisms of transportation have been reported for nanoparticles after intravenous and oral administration [22]. It is likely that after crossing the biological barriers, the nanoparticles are distributed throughout the body, a process that is also largely governed by the size of the particles. Small particles of $20-30 \mathrm{~nm}$ are eliminated by kidneys, while larger particles of up to $300 \mathrm{~nm}$ are taken up by the mononuclear phagocytic system [15]. Particles up to $200 \mathrm{~nm}$ display a longer blood circulation time due to decreased clearance [22]. Furthermore, particles can leak through the gaps of the endothelial lining, but generally they have to be smaller than $150 \mathrm{~nm}$ in diameter. However, larger particles have been reported to cross the endothelial barrier, because the fenestrations and the vascular lining suffer modifications in diverse pathological conditions [15]. For example, small nanoparticles can penetrate tumours and thus can be used as target drug delivery systems for treating cancer [53]. Taking this information into consideration, the ideal size for polymeric nanoparticles would be up to $200 \mathrm{~nm}$. Furthermore, larger particles have a smaller surface area and in general can incorporate more drug. In contrast, for smaller particles, most of the drug is in close proximity to the surface of the nanoparticles, thus providing a faster release. Therefore, the control of the size is a prerequisite for a desired drug release rate [50].

A search of the literature reveals that size is mostly affected by the type and concentration of polymer used to obtain the nanoparticles, and also by the stabilizer, also in terms of type and amount. Process parameters such as the manufacturing method and conditions i.e. the stirring speed, can impact the size of the nanoparticles. In our study, based on previous research, we have selected the nanoprecipitation method as the most adequate technique to prepare polymeric nanoparticles.
Regarding the size distribution of nanoparticles, a small value for the polydispersity index indicates a homogeneous dispersion. Usually, the polydispersity index should be no greater than 0.5 in order to be acceptable [3].

The Zeta potential of nanoparticles is determined by the surface charge, and it is influenced by the matrix composition and the dispersion medium [50]. It is generally considered that particles with a Zeta potential ranging from $-10 \mathrm{mV}$ to $10 \mathrm{mV}$ have neutral charge. Meanwhile, a Zeta potential lower than $-30 \mathrm{mV}$ or higher than $30 \mathrm{mV}$ characterizes a very stable nanoparticle dispersion [12]. Unstable colloidal systems are prone to aggregation [2]. The surface charge influences the uptake, pharmacokinetics of the nanoparticles, and aggregation in the blood flow, which in turn are responsible for the efficacy of the treatment $[5,23]$. However, the existing information on the influence of the surface charge is not entirely clear, even contradictory. Reports state that negatively charged particles are more rapidly cleared from the circulation as opposed to neutral and positively charged particles. On the other hand, positively charged particles exhibited more interaction with the negatively charged membrane of macrophages, and are eliminated to a greater extent by phagocytosis compared to negatively charged particles [35]. Furthermore, nanoparticles with negative charge are taken up by cells more efficiently due to powerful interactions with the membranes [48]. Also, surface charge can promote nonspecific interactions with other components from biological fluids [5]. Thus, we have considered acceptable a Zeta potential lower than $-30 \mathrm{mV}$, which should ensure reasonable stability for the nanoparticles. According to the literature, Zeta potential is mostly influenced by the type of polymer used in the formulation. We have chosen PLGA as the matrixforming polymer as it is an effective biodegradable polymer for obtaining nanoparticles; it is biocompatible, non-toxic and has been approved for human use by the regulatory agencies such as the US Food and Drug Administration (FDA) and European Medicines Agency (EMA) [31].

In order to be effective, the nanoparticles have to deliver and release the necessary dose of drug to the intended site of action. In this regard, high drug entrapment efficiency should be an objective in nanoparticle development. A high percentage of incorporated drug also means exposing the body to a reduced amount of excipients during administration [50]. In our study, QC was selected as drug substance to be encapsulated in the nanoparticles. The incorporation of a lipophilic drug in a lipophilic polymeric matrix has been reported to be feasible and yield acceptably high entrapment efficiency. In the present study, the optimal QC entrapment efficiency was considered above $50 \%$. 
The risk assessment was carried out to identify critical process parameters (CPPs) and critical material attributes (CMAs) causing variability in the selected CQAs of QC-loaded nanoparticles. Therefore, an Ishikawa diagram (Figure 2) was generated and used to organize the potential risk factors. The risk factors included in the Ishikawa diagram were divided into three categories, i.e. formulation, environmental and process, and helped identify the failure modes. The factors considered in the FMEA method and the corresponding RPNs are listed in Table IV. The RPNs aided in establishing the factors which posed the most risk to the CQAs of QC-loaded nanoparticles. The factors with a RPN above 30 were considered of high risk and, thus, needed to be investigated in more detail. Among the studied parameters, six risk factors showed high RPNs (>30), and were thus considered to potentially affect the quality of the final product. These variables were selected to be further investigated by means of experimental design to establish the degree of the impact on the product's CQAs.

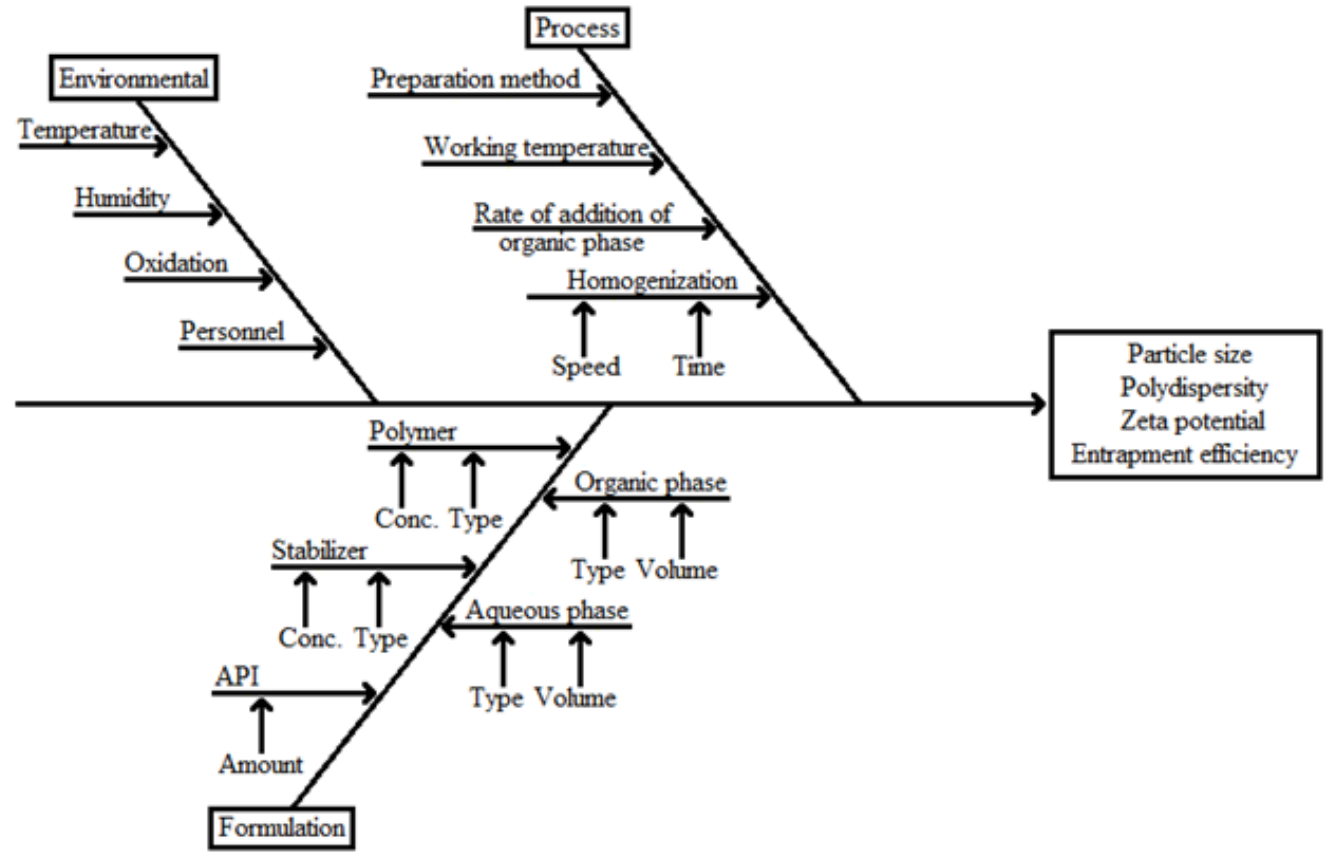

Figure 2.

Ishikawa diagram showing the impact of various risk factors on the CQAs of QC-loaded nanoparticles Conc. - Concentration; API - Active Pharmaceutical Ingredient

Table IV

FMEA of risk factors on the CQAs of QC-loaded nanoparticles

\begin{tabular}{llllcc}
\hline \multicolumn{1}{c}{ Risk factor category } & \multicolumn{1}{c}{ Risk factor } & O & S & D & RPN (O x S x D) \\
\hline Environmental factors & Temperature & 2 & 2 & 3 & 12 \\
& Humidity & 2 & 2 & 2 & 8 \\
& Oxidation & 2 & 2 & 3 & 12 \\
& Personnel & 1 & 1 & 3 & 3 \\
Process factors & Preparation method & 2 & 2 & 1 & 4 \\
& Temperature & 2 & 2 & 3 & 12 \\
& Homogenization speed & 4 & 4 & 3 & 48 \\
& Homogenization time & 2 & 2 & 3 & 12 \\
Formulation factors & Rate of addition of organic phase & 3 & 2 & 3 & 18 \\
& API amount & 4 & 4 & 3 & 48 \\
& Polymer type & 2 & 2 & 1 & 4 \\
& Polymer concentration & 4 & 5 & 3 & 60 \\
& Stabilizer type & 2 & 2 & 1 & 4 \\
& Stabilizer concentration & 4 & 5 & 3 & 60 \\
& Organic phase type & 2 & 2 & 1 & 4 \\
& Organic phase volume & 4 & 4 & 3 & 48 \\
& Aqueous phase type & 2 & 2 & 1 & 4 \\
& Aqueous phase volume & 4 & 4 & 3 & 48 \\
\hline
\end{tabular}

$\mathrm{O}$ - Occurrence; S - Severity; D - Detectability; RPN - Risk Priority Number; API - Active Pharmaceutical Ingredient 
Experimental design

The quality of fit of the model was expressed as $\mathrm{R}^{2}$ which is the coefficient of determination, while the predictive power was evaluated through $\mathrm{Q}^{2}$ called the coefficient of prediction. According to Figure 3, for each of the four investigated responses, the model showed a good fit and predictive power, as both $\mathrm{R}^{2}$ and $\mathrm{Q}^{2}$ had high values. Furthermore, the model validity and reproducibility also had sufficiently high values for the chosen model to be considered adequate.

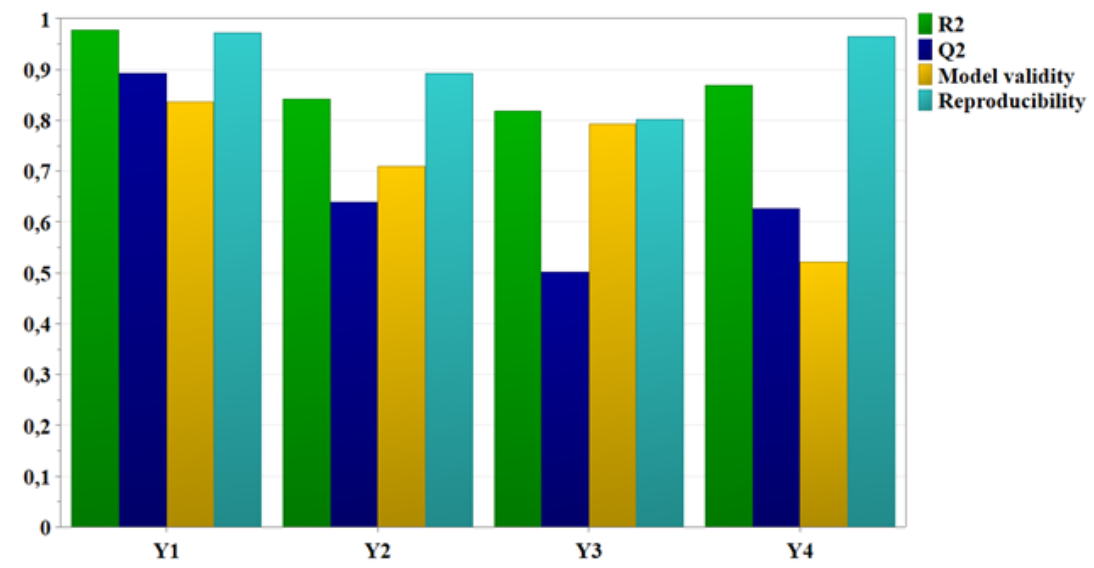

Figure 3.

Summary of fit results

Table V

Results for Analysis of variance (ANOVA)

\begin{tabular}{ccccccc}
\hline Dependent variable & $\boldsymbol{d} \boldsymbol{f}$ & SS & MS (variance) & $\boldsymbol{F}$ & p-value & Lack of fit \\
\hline $\mathrm{Y}_{1}$ & 6 & 44613.10 & 7435.51 & 88.65 & 0.000 & 0.522 \\
$\mathrm{Y}_{2}$ & 6 & 0.0097 & 0.0016 & 9.83 & 0.001 & 0.315 \\
$\mathrm{Y}_{3}$ & 7 & 817.06 & 116.72 & 7.07 & 0.002 & 0.438 \\
$\mathrm{Y}_{4}$ & 5 & 6582.98 & 1316.60 & 17.26 & 0.000 & 0.148 \\
\hline
\end{tabular}

$\mathrm{Y}_{1}-\operatorname{Size}(\mathrm{nm}) ; \mathrm{Y}_{2}-$ Polydispersity index; $\mathrm{Y}_{3}-$ Zeta potential $(\mathrm{mV}) ; \mathrm{Y}_{4}-$ Entrapment efficiency (\%); $d f$ - Degrees of freedom; SS - Sum of squares; MS - Mean of square; $F$ - Fisher's ratio; $\mathrm{p}$ - Probability

The results from the ANOVA test (Table V) indicate that the model was significant $(p<0.05)$. Moreover, the lacks of fit values for the model were not significant $(\mathrm{p}>0.05)$.
Model regression coefficients plots emphasize the effect of variables on the response. These coefficients are presented as histograms in Figure 4.
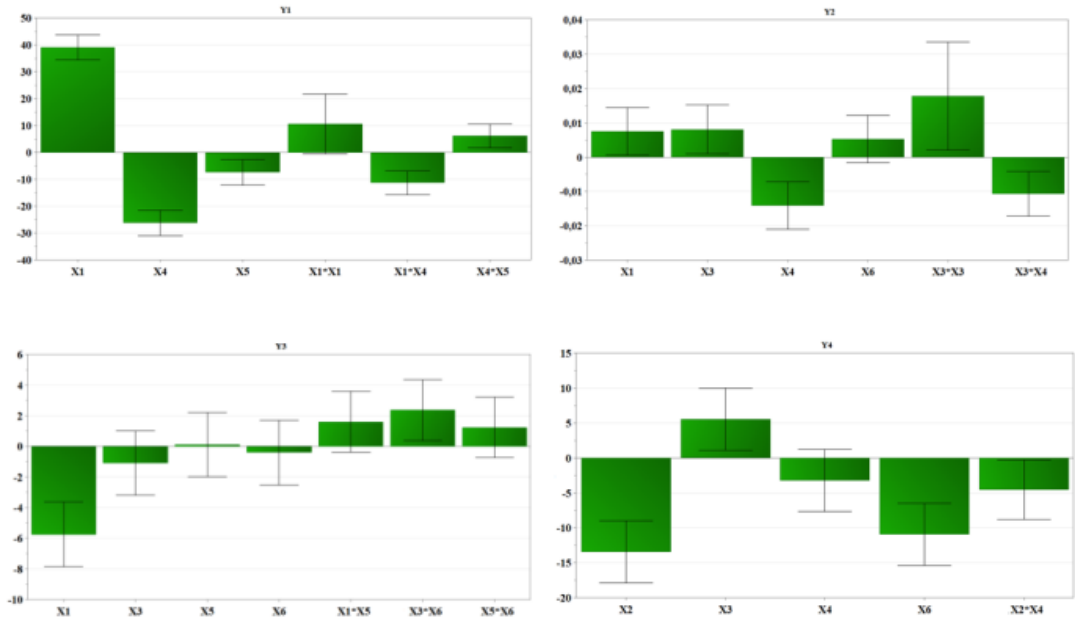

Figure 4.

Regression coefficients plots indicating the effect of the independent variables on the responses

$\mathrm{Y}_{1}-$ Size $(\mathrm{nm}) ; \mathrm{Y}_{2}$ - Polydispersity index; $\mathrm{Y}_{3}$ - Zeta potential (mV); $\mathrm{Y}_{4}$ - Entrapment efficiency (\%); $\mathrm{X}_{1}$ - PLGA concentration (mg/mL); $\mathrm{X}_{2}-$ PVA concentration $(\% \mathrm{w} / \mathrm{v}) ; \mathrm{X}_{3}-\mathrm{QC}$ concentration $(\mathrm{mg} / 10 \mathrm{~mL}) ; \mathrm{X}_{4}-$ Acetone volume $(\mathrm{mL}) ; \mathrm{X}_{5}-$ Stirring speed (rpm); $\mathrm{X}_{6}-$ Aqueous phase volume $(\mathrm{mL})$ 
FARMACIA, 2018, Vol. 66, 5

Influence of variables on the particle size $\left(Y_{l}\right)$ The QC-loaded nanoparticles were nanosized, their diameter varying between $146.30 \pm 0.67 \mathrm{~nm}$ and $309.00 \pm 4.20 \mathrm{~nm}$. According to the ANOVA results for the nanoparticle size, the $p$ value was $p=0.000$ and the lack of fit was $p=0.522$, thus the model proved a good fit to the data and no lack of fit.

The nanoprecipitation method employed in the present study implies the precipitation of PLGA from an organic solution as a result of the organic solvent's diffusion into an aqueous medium. Nanoparticles form through the deposition of the polymer at the interface between the organic and aqueous solutions [12].

As shown in Figure 4, the PLGA concentration significantly influenced the nanoparticles' size. The greater the polymer concentration, the larger the nanoparticles formed. The increase in nanoparticle size with the increase in PLGA concentration can be correlated with an increase in the viscosity of the organic medium due to polymer-polymer interactions [44]. Another possible explanation for the observed effects would be an insufficient amount of PVA covering the surface of the nanoparticles to stabilize them, resulting in aggregation of the particles [38]. Our findings are in agreement with those published by other research groups [9, 48].

In contrast, the volume of acetone and the stirring speed had opposite effects on the size of the nanoparticles. Larger nanoparticles were obtained when using a smaller volume of acetone and applying a lower stirring speed. For a constant PLGA concentration, decreasing the acetone volume or the stirring speed prevents the rapid diffusion of the organic solvent in the aqueous medium, and this in turn yields larger particles. Our findings are consistent with those reported by Jain et al and Reddy et al [20,44].
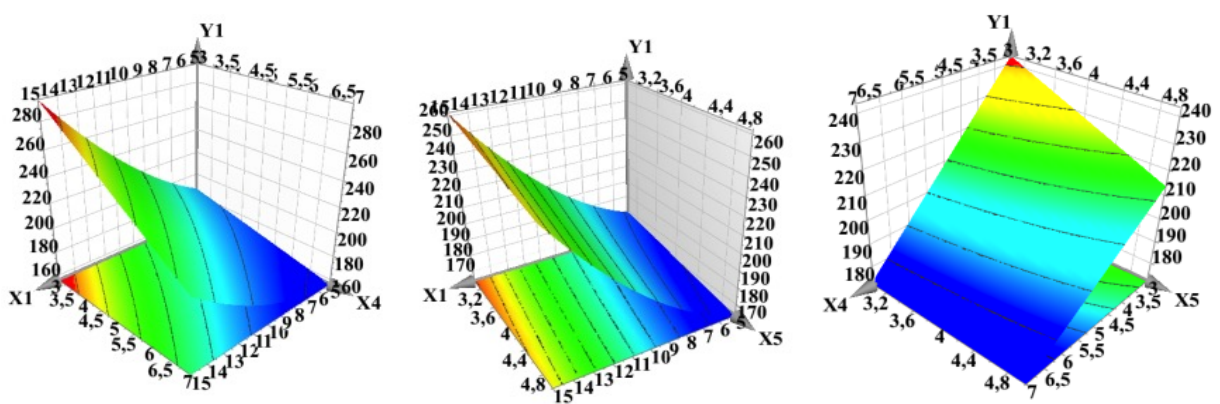

Figure 5.

Response surface plots showing the effect of independent variables on the size of the QC-loaded nanoparticles $\mathrm{Y}_{1}-$ Size $(\mathrm{nm}) ; \mathrm{X}_{1}-\mathrm{PLGA}$ concentration $(\mathrm{mg} / \mathrm{mL}) ; \mathrm{X}_{4}-$ Acetone volume $(\mathrm{mL}) ; \mathrm{X}_{5}-$ Stirring speed $(\mathrm{rpm})$

According to Figure 5, two interactions between the discussed variables have been identified and showed impact on the particle size. The interaction between the PLGA concentration and the acetone volume $\left(\mathrm{X}_{1} * \mathrm{X}_{4}\right)$ led to a decrease in particle size, while the interaction between the volume of acetone and the stirring speed $\left(\mathrm{X}_{4} * \mathrm{X}_{5}\right)$ produced larger size particles. Influence of variables on the PdI $\left(Y_{2}\right)$

The PdI ranged between a minimum value of $0.06 \pm$ 0.01 and a maximum value of $0.35 \pm 0.09$. Similar results were reported by Anwer et al for QC-loaded PLGA nanoparticles [4]. Results from the ANOVA test indicated a significant model $(\mathrm{p}=0.001)$ and absence of lack of fit $(p=0.315)$.

While the PLGA and the QC concentrations had a positive effect on the PdI, the acetone volume exhibited a negative one (Figure 4). As discussed above, the polymer concentration and the acetone volume directly influence the viscosity of the organic solvent and the rate of diffusion. It is possible that alongside larger particles, also smaller particles are obtained which translated into a population of particles of various sizes, thus bigger values for PdI.

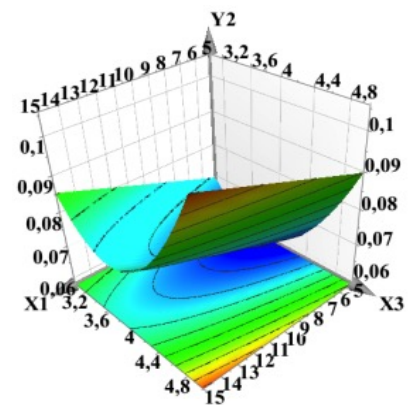

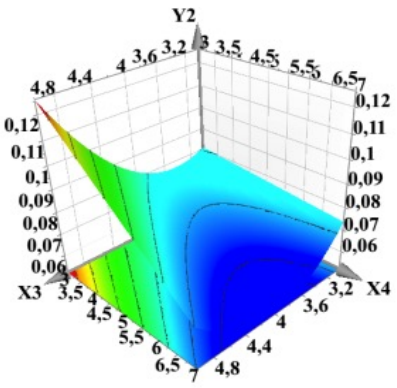

Figure 6

Response surface plots showing the effect of independent variables on the PdI of the QC-loaded nanoparticles $\mathrm{Y}_{2}$ - PdI; $\mathrm{X}_{1}$ - PLGA concentration $(\mathrm{mg} / \mathrm{mL}) ; \mathrm{X}_{3}-\mathrm{QC}$ concentration $(\mathrm{mg} / 10 \mathrm{~mL}) ; \mathrm{X}_{4}-$ Acetone volume $(\mathrm{mL})$ 
Increase in the QC concentration resulted in smaller PdI values up to the inflexion point on the response surface curve (Figure 6). Over this point (corresponding to approximatively $3.8 \mathrm{mg} / 10 \mathrm{~mL} \mathrm{QC}$ ), further increase in QC concentration led to an increase in polydispersity. Although it was not observed in the present study, it has been reported that the addition of a drug produces an expansion or reorganization of the polymer matrix, leading to larger particles [34]. It can be assumed that beyond the inflexion point, larger particles entrapping QC were obtained, but with increased size distribution.

Furthermore, Figure 4 indicates an interaction between the QC concentration and the volume of acetone $\left(\mathrm{X}_{3} * \mathrm{X}_{4}\right)$. It can be observed from the histogram that the QC concentration and the volume of organic solvent had a negative effect on the polydispersity of the nanoparticles.

Influence of variables on the Zeta potential $\left(Y_{3}\right)$

The nanoparticles' Zeta potential was found to range from $-35.50 \pm 0.55 \mathrm{mV}$ to $-3.69 \pm 0.91 \mathrm{mV}$. It is reported that in the absence of PVA or any other stabilizer, PLGA nanoparticles exhibit a negative Zeta potential of $-45 \mathrm{mV}$ which can be attributed to free carboxyl groups [28].

Formulations N4, N6, N8, N10 and N14 with Zeta potentials of $-32.90 \mathrm{mV},-31.70 \mathrm{mV},-30.90 \mathrm{mV}$, $-30.10 \mathrm{mV}$ and $-35.50 \mathrm{mV}$, respectively showed good stability, while the rest of the formulations were considered to have poor stability and susceptible to aggregation. However, these principles generally apply when surfactants with low molecular weight are used, and not for high molecular weight steric stabilizers like PVA [30]. Previous work has shown that nanoparticles prepared with PVA maintain a negative surface charge, but it shifts towards more positive values. By adsorption on the surface of the nanoparticles, PVA can shield the some of the PLGA's negative charges. Therefore, in spite of the measured Zeta potential, the nanoparticles could exhibit fairly good stability [30]. This explanation is supported by the data published by other researchers $[28,30]$. The statistical analysis for the Zeta potential showed the significance of the model $(p=0.002)$ and absence of lack of fit $(p=0.438)$.

The sole factor which influenced the Zeta potential was the PLGA concentration (Figure 4). The Zeta potential decreased with increasing polymer concentration. Our data are in agreement with those published by other authors [28].

The response surface plot (Figure 7) shows a strong interaction between the QC concentration and the volume of aqueous phase $\left(\mathrm{X}_{3} * \mathrm{X}_{6}\right)$ on the Zeta potential of the nanoparticles. It can be observed that an increase of the two variables exhibited a synergistic effect on the nanoparticles' surface charge.

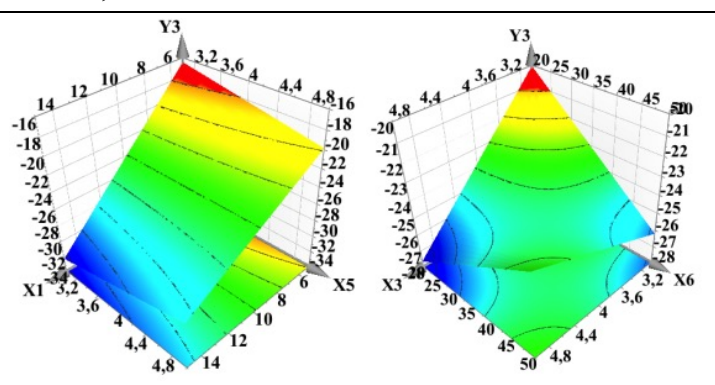

Figure 7.

Response surface plots showing the effect of independent variables on the Zeta potential of the QC-loaded nanoparticles

$\mathrm{Y}_{3}-$ Zeta potential $(\mathrm{mV}) ; \mathrm{X}_{1}-\mathrm{PLGA}$ concentration $(\mathrm{mg} / \mathrm{mL})$; $\mathrm{X}_{3}-\mathrm{QC}$ concentration $(\mathrm{mg} / 10 \mathrm{~mL}) ; \mathrm{X}_{5}-$ Stirring speed $(\mathrm{rpm})$; $\mathrm{X}_{6}-$ Aqueous phase volume $(\mathrm{mL})$

Influence of variables on the entrapment efficiency $\left(Y_{4}\right)$ The percentage of entrapped QC varied on a wide range from $10.19 \%$ to $85.36 \%$. For the entrapment efficiency, the model showed a satisfactory fit to the experimental data as the $p$ value was $p=0.000$ and had no lack of fit $(\mathrm{p}=0.148)$.

The entrapment efficiency was mostly affected by the PVA concentration and the volume of aqueous phase (Figure 8). The two independent variables are negatively correlated with the entrapment efficiency, meaning that an increase in either one of them determined a decrease in the percentage of entrapped QC. The PVA molecules are deposited at the interface between the organic and aqueous phases, thus lowering the free energy and preventing the coalescence of particles [49]. The concentration of stabilizer has an important effect on the nanoparticles' properties. Although in our study we could not highlight the relation between the PVA concentration and the size of the nanoparticles, other groups report that, generally, increasing the PVA concentration yields nanoparticles of smaller size [59]. It can be assumed that smaller size particles can entrap a smaller amount of drug. However, at high concentrations of stabilizer, the entrapment of the drug is also reduced due to the interaction between PVA and QC [16], namely an increased solubility of QC in the aqueous phase [51]. Thus, less QC will remain in the organic phase to be incorporated in the PLGA nanoparticles.

The QC entrapment efficiency decreased dramatically with increase in the volume of aqueous phase. Upon the addition of the organic phase, the drug is partitioned between the two phases and diffuses in the aqueous medium. Additionally, the greater the volume of aqueous phase the greater the amount of dissolved QC. This results in less QC retained in the organic phase to interact with the polymer [38].

Of less magnitude than the previously discussed variables was the effect of the QC concentration which positively influenced its own entrapment 

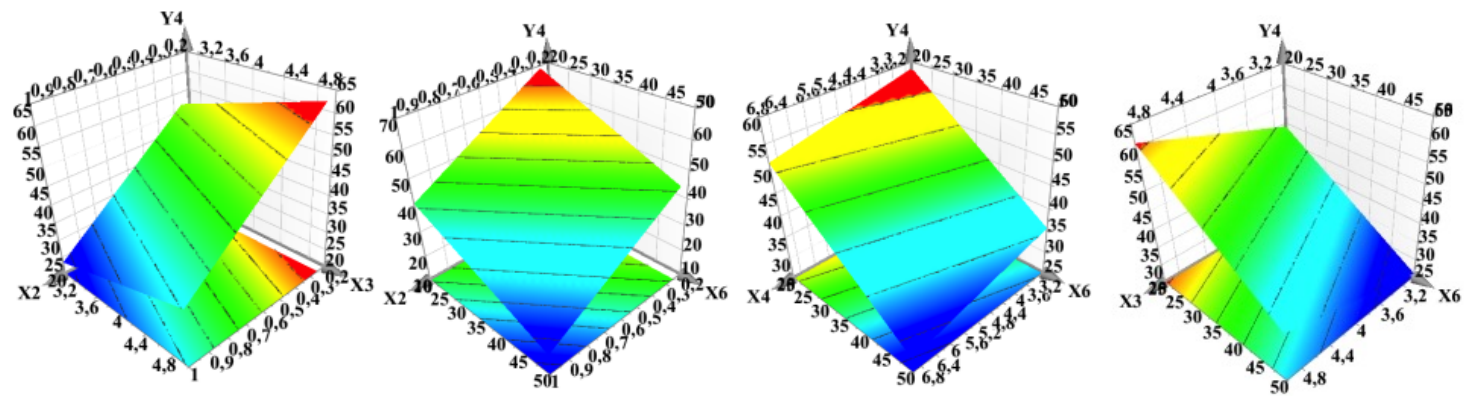

Figure 8.

Response surface plots showing the effect of independent variables on the entrapment efficiency of the QCloaded nanoparticles

$\mathrm{Y}_{4}$ - Entrapment efficiency (\%); $\mathrm{X}_{2}$ - PVA concentration (\% w/v); $\mathrm{X}_{3}-\mathrm{QC}$ concentration $(\mathrm{mg} / 10 \mathrm{~mL}) ; \mathrm{X}_{4}-$ Acetone volume $(\mathrm{mL}) ;$ $\mathrm{X}_{6}-$ Aqueous phase volume $(\mathrm{mL})$

We observed an interaction between the PVA concentration and the volume of acetone $\left(\mathrm{X}_{2} * \mathrm{X}_{4}\right)$ on the entrapment efficiency (Figure 4). Increase in these two variables led to a drop in the percentage of entrapped QC. The influence of the PVA concentration was previously discussed. Concerning the organic phase effect, a larger volume of acetone requires more time for removal during the evaporation step, which favours the partition of QC in the aqueous phase [51]. Furthermore, the co-solvency effect of the acetone for QC could account for the decrease in the entrapment efficiency [38].

\section{Conclusions}

Pharmaceutical product manufacturing has known significant advancement since the regulatory authorities have encouraged the use of scientific and systematic tools of development like QbD. The basic goal of $\mathrm{QbD}$ is to provide a product with desired quality in a cost effective way by controlling the manufacturing process and minimizing the potential risk associated with the development process.

The present study shows that QC-loaded polymeric nanoparticles can be successfully designed by implementing the $\mathrm{QbD}$ approach. The nanoprecipitation method was employed to prepare PLGA nanoparticles entrapping an antioxidant drug, namely QC. Taking into account the wide range of risk sources that could affect product quality, an Ishikawa diagram and FMEA method were used to rank the risk and identify the highly influential risk factors. Thus, it was possible to reduce the number of risk factors down to six, namely, the concentrations of PLGA, PVA, QC, the volumes of organic and aqueous phases and the stirring speed. Design of experiments was used to understand the effects of these formulation factors and process parameters on the CQAs of QCloaded nanoparticles. Our results indicate that formulation and process variables influence the quality of polymeric nanoparticles to a different extent. In this regard, the QbD method helped prioritize the risks associated in the process and identify the main variables impacting the QC-loaded nanoparticles' CQAs.

On the basis on the obtained results, it can be concluded that the selected experimental domain was relevant and adequately chosen. However, additional studies are needed to optimize the preparation of QC-loaded PLGA nanoparticles. In this regard, the variables with most impact on the nanoparticles' CQAs, namely, the PGLA and PVA concentrations and the stirring speed warrant further studies. To get more insight into their effect on the CQAs, we propose expanding the range of variation for the three selected variables in a future study. Therefore, we opt for the following setup: PLGA concentration 5 - $20 \mathrm{mg} / \mathrm{mL}$, PVA concentration $1-4 \%$ and stirring speed 255 - $510 \mathrm{rpm}$. The other three investigated variables in the present study, namely the QC concentration, the acetone volume and the aqueous phase volume, will be set at levels which, according to the multivariate analysis in the present study, led to reasonable results for size, PdI, Zeta potential and entrapment efficiency (5 mg QC, $7 \mathrm{~mL}$ acetone, $35 \mathrm{~mL}$ aqueous phase). In the given scenario, we propose to establish an optimum formulation for the QC-loaded polymeric nanoparticles.

\section{References}

1. Agrawal P, Significance of Polymers in Drug Delivery System. J Pharmacovigil., 2014; 3(1): e127.

2. Alai MS, Lin WJ, Pingale SS, Application of polymeric nanoparticles and micelles in insulin oral delivery. J Food Drug Anal., 2015; 23: 351-358.

3. Amasya G, Badilli U, Aksu B, Tarimci N, Quality by design case study 1: Design of 5-fluorouracil loaded lipid nanoparticles by the $\mathrm{W} / \mathrm{O} / \mathrm{W}$ double emulsion Solvent evaporation method. Eur J Pharm Sci., 2016; 84: 92-102.

4. Anwer MK, Al-Mansoor MA, Jamil S, Al-Shdefat R, Ansari MN, Shakeel F, Development and evaluation 
of PLGA polymer based nanoparticles of quercetin. Int J Biol Macromol., 2016; 92: 213-219.

5. Ayala V, Herrera AP, Latorre-Esteves M, Torres-Lugo M, Rinaldi C, Effect of surface charge on the colloidal stability and in vitro uptake of carboxymethyl dextrancoated iron oxide nanoparticles. J Nanopart Res., 2013; 15(8): 1874.

6. Ban C, Park SJ, Lim S, Choi SJ, Choi YJ, Improving Flavonoid Bioaccessibility using an Edible Oil-Based Lipid Nanoparticle for Oral Delivery. J Agric Food Chem., 2015; 63(21): 5266-5272.

7. Bolhassani A, Javanzad S, Saleh T, Hashemi M, Sadat SM, Polymeric nanoparticles: potent vectors for vaccine delivery targeting cancer and infectious diseases. Hum Vaccin Immunother., 2014; 10(2): 321-332.

8. Cevher E, Orhan Z, Șensoy D, Ahiskali R, Kan PL, Sağirli O, Mülazimoğlu L, Sodium fusidate-poly (D,L-lactide-co-glycolide) microspheres: Preparation, characterisation and in vivo evaluation of their effectiveness in the treatment of chronic osteomyelitis. J Microencapsul., 2007; 24(6): 577-595.

9. Cun D, Jensen DK, Maltesen MJ, Bunker M, Scurr D, Foged C, Nielsen HM, High loading efficiency and sustained release of siRNA encapsulated in PLGA nanoparticles: Quality by design optimization and characterization. Eur J Pharm Biopharm., 2011; 77: 26-35.

10. De Jong WH, Borm PJA, Drug delivery and nanoparticles: Applications and hazards. Int J Nanomed., 2008; 3(2): 133-149.

11. Dian L, Yu E, Chen X, Wen X, Zhang Z, Qin L, Li G, Wu C, Enhancing oral bioavailability of quercetin using novel soluplus polymeric micelles. Nanoscale Res Lett., 2014; 9: 684.

12. dos Santos KC, da Silva MFGF, Pereira-Filho ER, Fernandes JB, Polikarpov I, Forim MR, Polymeric nanoparticles loaded with the 3,5,3'-triiodothyroacetic acid (Triac), a thyroid hormone: factorial design, characterization, and release kinetics. Nanotechnol Sci Appl., 2012; 5: 37-48.

13. El-kader FHA, Osman WH, Mahmoud KH, Basha MAF, Dielectric investigations and ac conductivity of polyvinyl alcohol films doped with europium and terbium chloride. Physica B, 2008; 403: 3473-3484.

14. Fessi H, Puisieux F, Devissaguet JP, Ammoury N, Benita S, Nanocapsule formation by interfacial polymer deposition following solvent displacement. Int $J$ Pharm., 1989; 55(1): R1-R4.

15. Gaumet M, Vargas A, Gurny R, Delie F, Nanoparticles for drug delivery: The need for precision in reporting particle size parameters. Eur J Pharm Biopharm., 2008; 69: 1-9.

16. Hariharan S, Bhardwaj V, Bala I, Sitterberg J, Bakowsky U, Kumar MNVR, Design of Estradiol Loaded PLGA Nanoparticulate Formulations: A Potential Oral Delivery System for Hormone Therapy. Pharm Res., 2006; 23(1): 184-195.

17. ICH Harmonised Tripartite Guideline. Pharmaceutical Devel $\neg$ opment Q8(R2). www.ich.org.

18. Jahangirian H, Lemraski EG, Webster TJ, RafieeMoghaddam R, Abdollahi Y, A review of drug delivery systems based on nanotechnology and green chemistry: green nanomedicine. Int J Nanomedicine, 2017; 12: 2957-2978
19. Jain AK, Thanki K, Jain S, Co-encapsulation of tamoxifen and quercetin in polymeric nanoparticles: Implications on oral bioavailability, antitumor efficacy and drug induced toxicity. Mol Pharm., 2013; 10(9): 3459-3474.

20. Jain S, Saraf S, Influence of processing variables and in vitro characterization of glipizide loaded biodegradable nanoparticles. Diabetes Metab Syndr., 2009; 3: 113117.

21. Kakran M, Sahoo NG, Li L, Judeh Z, Fabrication of quercetin nanoparticles by anti-solvent precipitation method for enhanced dissolution. Powder Technol., 2012; 223: 59-64.

22. Kulkarni SA, Feng SS, Effects of Particle Size and Surface Modification on Cellular Uptake and Biodistribution of Polymeric Nanoparticles for Drug Delivery. Pharm Res., 2013; 30: 2512-2522.

23. Kumari A, Yadav SK, Yadav SC, Biodegradable polymeric nanoparticles based drug delivery systems. Colloids Surf B Biointerfaces, 2010; 75: 1-18.

24. Li H, Zhao X, Ma Y, Zhai G, Li L, Enhancement of gastrointestinal absorption of quercetin by solid lipid nanoparticles. J Control Release, 2009; 133: 238-244.

25. Liechty WB, Kryscio DR, Slaughter BV, Peppas NA, Polymers for Drug Delivery Systems. Annu Rev Chem Biomol Eng., 2010; 1: 149-173.

26. Lionberger RA, Lee SL, Lee L, Raw A, Yu LX, Quality by Design: Concepts for ANDAs. AAPS J., 2008; 10(2): 268-276.

27. Makadia HK, Siegel SJ, Poly Lactic-co-Glycolic Acid (PLGA) as Biodegradable Controlled Drug Delivery Carrier. Polymers (Basel), 2011; 3(3): 1377-1397.

28. Manchanda R, Fernandez-Fernandez A, Nagesetti A, McGoron AJ, Preparation and characterization of a polymeric (PLGA) nanoparticulate drug delivery system with simultaneous incorporation of chemotherapeutic and thermo-optical agents. Colloids Surf B Biointerfaces, 2010; 75(1): 260-267.

29. Marin E, Briceño MI, Caballero-George C, Critical evaluation of biodegradable polymers used in nanodrugs. Int J Nanomedicine, 2013; 8: 3071-3091.

30. Miladi K, Sfar S, Fessi H, Elaissari A, Encapsulation of alendronate sodium by nanoprecipitation and double emulsion: From preparation to in vitro studies. Ind Crops Prod., 2015; 72: 24-33.

31. Mirakabad FST, Nejati-Koshki K, Akbarzadeh A, Yamchi MR, Milani M, Zarghami N, Zeighamian V, Rahimzadeh A, Alimohammadi S, Hanifehpour Y, Joo SW, PLGA-Based Nanoparticles as Cancer Drug Delivery Systems. Asian Pac J Cancer Prev., 2014; 15(2): 517-535.

32. Mogal V, Dusane J, Borase P, Thakare P, Kshirsagar $\mathrm{S}$, A review on quality by design. Pharmac Biolog Evaluations, 2016; 3(3): 313-319.

33. Mora-Huertas CE, Fessi H, Elaissari A, Polymerbased nanocapsules for drug delivery. Int J Pharm., 2010; 385: 113-142.

34. Musumeci T, Ventura CA, Giannone I, Ruozi B, Montenegro L, Pignatello R, Puglisi G, PLA/PLGA nanoparticles for sustained release of docetaxel. Int J Pharm., 2006; 325: 172-179.

35. Nandhakumar S, Dhanaraju MD, Sundar VD, Heera $\mathrm{B}$, Influence of surface charge on the in vitro protein adsorption and cell cytotoxicity of paclitaxel loaded 
FARMACIA, 2018, Vol. 66, 5

poly( $\varepsilon$-caprolactone) nanoparticles. $B-F O P C U$, 2017; 55: 249-258.

36. Pallagi E, Ambrus R, Szabó-Révész P, Csóka I, Adaptation of the quality by design concept in early pharmaceutical development of an intranasal nanosized formulation. Int J Pharm., 2015; 491: 384-392.

37. Palle S, Neerati P, Quercetin nanoparticles attenuates scopolamine induced spatial memory deficits and pathological damages in rats. $B-F O P C U, 2017$; 55 : 101-106.

38. Pimple S, Manjappa AS, Ukawala M, Murthy RSR, PLGA nanoparticles loaded with etoposide and quercetin dihydrate individually: in vitro cell line study to ensure advantage of combination therapy. Cancer Nanotechnol., 2012; 3(1-6): 25-36.

39. Pool H, Quintanar D, Figueroa JD, Mano CM, Bechara JEH, Godínez LA, Mendoza S, Antioxidant Effects of Quercetin and Catechin Encapsulated into PLGA Nanoparticles. J Nanomater., 2012; 2012: 1-12.

40. Prabhu RH, Patravale VB, Joshi MD, Polymeric nanoparticles for targeted treatment in oncology: current insights. Int J Nanomed., 2015; 10: 1001-1018.

41. Pramod K, Tahir MA, Charoo NA, Ansari SH, Ali J, Pharmaceutical product development: A quality by design approach. Int J Pharm Investig., 2016; 6(3): 129-138.

42. Raman NVVSS, Mallu UR, Bapatu HR, Analytical Quality by Design Approach to Test Method Development and Validation in Drug Substance Manufacturing. J Chem., 2015; 2015: 1-8.

43. Rayaprolu BM, Quality by Design: A Brief Introduction. J Pharmacovigil., 2015; 3(4): e142.

44. Reddy PRV, Acharya SR, Acharya NS, Optimization of size controlled poly (lactide-co-glycolic acid) nanoparticles using quality by design concept. Asian $J$ Pharm., 2015; 9(3): 152-161.

45. Saha C, Kaushik A, Das A, Pal S, Majumder D, Anthracycline Drugs on Modified Surface of QuercetinLoaded Polymer Nanoparticles: A Dual Drug Delivery Model for Cancer Treatment. PLoS One, 2016; 11(5): e0155710.

46. Sahoo SK, Labhasetwar V, Nanotech approaches to drug delivery and imaging. Drug Discov Today, 2003; 8(24): 1112-1120.

47. Sangshetti JN, Deshpande M, Zaheer Z, Shinde DB, Arote R, Quality by design approach: Regulatory need. Arab J Chem., 2017; 10: S3412-S3425.

48. Sharma D, Maheshwari D, Philip G, Rana R, Bhatia S, Singh M, Gabrani R, Sharma SK, Ali J, Sharma RK, Dang S, Formulation and optimization of polymeric nanoparticles for intranasal delivery of lorazepam using Box-Behnken design: In Vitro and In Vivo Evaluation. Biomed Res Int., 2014; 2014: 1-14.
49. Sharma N, Madan P, Lin S, Effect of process and formulation variables on the preparation of parenteral paclitaxel-loaded biodegradable polymeric nanoparticles: A co-surfactant study. AJPS, 2016; 11(3): 404-416.

50. Singh R, Lillard JWJr, Nanoparticle-based targeted drug delivery. Exp Mol Pathol., 2009; 86(3): 215-223.

51. Song X, Zhao Y, Hou S, Xu F, Zhao R, He J, Cai Z, Dual agents loaded PLGA nanoparticles: Systematic study of particle size and drug entrapment efficiency. Eur J Pharm Biopharm., 2008; 69: 445-453.

52. Srivastava A, Yadav T, Sharma S, Nayak A, Kumari A, Mishra N, Polymers in Drug Delivery. J Biosci Med., 2016; 4: 69-84.

53. Stevanović M, Uskoković D, Poly(lactide-co-glycolide)based Micro and Nanoparticles for the Controlled Drug Delivery of Vitamins. Curr Nanosci., 2009; 5(1): 1-14.

54. Sun D, Li N, Zhang W, Yang E, Mou Z, Zhao Z, Liu H, Quercetin-loaded PLGA nanoparticles: a highly effective antibacterial agent in vitro and anti-infection application in vivo. $J$ Nanopart Res., 2016; 18(3): 1-21.

55. Suri SS, Fenniri H, Singh B, Nanotechnology-based drug delivery systems. J Occup Med Toxicol., 2007; 2: 16 .

56. Sutradhar KB, Amin ML, Nanotechnology in Cancer Drug Delivery and Selective Targeting. ISRN Nanotechnology, 2014; 2014: 1-12.

57. Tefas LR, Muntean DM, Vlase L, Porfire AS, Achim M, Tomuţă I, Quercetin-loaded liposomes: formulation optimization through a D-optimal experimental design. Farmacia, 2015; 63(1): 26-33.

58. Vijayakumar A, Baskaran R, Jang YS, Oh SH, Yoo BK, Quercetin-Loaded Solid Lipid Nanoparticle Dispersion with Improved Physicochemical Properties and Cellular Uptake. AAPS PharmSciTech., 2017; 18(3): 875-883.

59. Yallapu MM, Gupta BK, Jaggi M, Chauhan SC, Fabrication of curcumin encapsulated PLGA nanoparticles for improved therapeutic effects in metastatic cancer cells. J Colloid Interface Sci., 2010; 351: 19-29.

60. Yu LX, Amidon G, Khan MA, Hoag SW, Polli J, Raju GK, Woodcock J, Understanding Pharmaceutical Quality by Design. AAPS J., 2014; 16(4): 771-783.

61. Yuan Z, Chen L, Fan L, Tang M, Yang G, Yang H, Du X, Wang G, Yao W, Zhao Q, Ye B, Wang R, Diao P, Zhang W, Wu H, Zhao X, Liposomal Quercetin Efficiently Suppresses Growth of Solid Tumors in Murine Models. Clin Cancer Res., 2006; 12(10): 3193-3199.

62. Zhang L, Mao S, Application of quality by design in the current drug development. AJPS, 2017; 12: 1-8. 